\title{
ADVANCING THE HYDROGEN SAFETY KNOWLEDGE BASE
}

\author{
S.C. Weiner \\ Pacific Northwest National Laboratory, Washington, DC 20024, USA, sc.weiner@pnnl.gov
}

\begin{abstract}
The International Energy Agency's Hydrogen Implementing Agreement (IEA HIA) was established in 1977 to pursue collaborative hydrogen research and development and information exchange among its member countries. Information and knowledge dissemination is a key aspect of the work within IEA HIA tasks, and case studies, technical reports and presentations/publications often result from the collaborative efforts. The work being conducted in hydrogen safety under Task 31 and its predecessor, Task 19, can positively impact the objectives of national programs even in cases for which a specific task report is not published. The interactions within Task 31 are illustrating how technology information and knowledge exchange among participating hydrogen safety experts are serving the objectives intended by the IEA HIA.
\end{abstract}

\subsection{INTRODUCTION}

The International Energy Agency's Hydrogen Implementing Agreement (IEA HIA) was established in 1977 to pursue collaborative hydrogen research and development and information exchange among its member countries. The IEA HIA mission serves to "accelerate hydrogen implementation and widespread utilization to optimize environmental protection, improve energy security and promote economic development internationally while establishing the IEA HIA as a premier global resource for expertise in hydrogen" [1]. A presentation at the World Hydrogen Energy Conference highlighted the breadth of the IEA HIA scope in over 30 task areas and its reach among member countries [2].

The work in hydrogen safety serves as a good example of how collaboration is working within the IEA HIA. Ten member countries and the European Commission participate in Task 31 (2010-2013). Its predecessor, Task 19 (2004-2010), formed the basis for illustrating how such cost-effective, taskshared activities can combine the efforts of the best hydrogen safety experts. A coordinated approach in collaborative research and development and information exchange can positively influence national programs by minimizing duplication of effort toward achieving mutually beneficial objectives.

Information and knowledge dissemination is a key aspect of the work within IEA HIA tasks and case studies. Technical reports, presentations and publications often result from the collaborative efforts focused by a task work plan. For example, the work of Task 19 resulted in several reports that can be found on the IEA HIA website, http://ieahia.org/ [3-5]. Examples abound to illustrate that even in cases for which a specific task report is not published, these collaborations can positively influence the objectives of national programs. A white paper published by Task 19 highlights how hydrogen safety knowledge tools in the form of publicly available databases, websites and specialized software were enhanced by the work of member countries [6].

The work now being conducted within Task 31 is focused in four subtask areas:

- Subtask A - Physical Effects and Knowledge Gaps

- Subtask B - Storage Systems and Materials Compatibility

- Subtask C - Early Markets: Risk Characterization and Hazard Analysis

- Subtask D - Knowledge Analysis, Dissemination and Use

The interactions within Task 31 are illustrating how technology information and knowledge exchange among participating hydrogen safety experts, while often underreported, is serving IEA HIA objectives. The purpose of this white paper is to provide specific examples to that point that have resulted from the collaborations within Task 31 or those in Task 19 not previously reported. 


\subsection{DEVELOPING UNIFORM RISK AND HARM CRITERIA}

The development of science-based and risk-informed regulations, codes and standards (RC\&S) continues to be an important focus area for Task 31. Insights on the risk associated with hydrogen facility operations are being obtained by Sandia National Laboratories (SNL) using quantitative risk assessment (QRA) and are being used to inform the requirements in RC\&S. Public acceptance of a hydrogen facility design and operation should be determined by whether the hazards and their associated risks meet established risk criteria or guidelines. A Task 19 report on knowledge gaps [3] noted that establishment of harm and risk criteria are a key element required to utilize a risk-informed approach for developing hydrogen RC\&S for hydrogen facility operation.

The performance of QRAs requires that the level of harm that is represented in the risk evaluation be established using deterministic models. The level of harm is a function of the type and level of hazard and other factors that are dependent upon the hazard. For fires, important factors include the exposure time to the hazard, the amount and location of exposure, the type and amount of protective clothing and the age of an exposed person. Hazard is defined as the potential source of harm, while harm is defined as physical injury or damage to the health of people, or damage to property or the environment [7].

The principal hazards associated with hydrogen facilities are fires and explosions resulting from the uncontrolled release of hydrogen and subsequent ignition. The primary consequences of fire hazards are personnel injury or fatalities, or facility and equipment damage due to high air temperatures, radiant heat fluxes or direct contact with hydrogen flames. The possible consequences of explosions for humans and structures or equipment include blast wave overpressure effects, effects of fragments generated by the explosion, the collapse of buildings and the heat effects from subsequent fire balls. A harm criterion is used to translate the consequences of an accident, evaluated from deterministic models, to a probability of harm to people, structures or components. Different methods can be used to establish harm criteria, including the use of threshold consequence levels and continuous functions that relate the level of a hazard to a probability of damage.

In addition to harm criteria, risk criteria must be established to determine the adequacy of a hydrogen facility or the requirements in RC\&S. Risk is defined as the combination of the probability of occurrence of harm and the severity of that harm [7]. Since the primary concern for hydrogen-related accidents is the potential for personnel injury or fatalities, risk criteria can be established for all the people exposed to the consequences of facility-related accidents, which could include the public located outside the boundaries of the facility, users of the facility or customers, and the facility workers. Risk criteria for members of the public can be further specified with regard to individuals or the population at large. The selection of personnel risk criteria should be based on sound arguments and reflect the consensus of all stakeholders. Ideally, the risk associated with the widespread development of hydrogen refueling stations should not substantially increase injury or fatality risk of an individual or society. Risk criteria related to facility damage or environmental effects can also be established and expressed as monetary values.

Task 19 represented an invaluable means to engage subject matter experts in the consideration of these criteria. By comparing various risk assessment studies and methodologies, both qualitative and quantitative, the experts group was able to develop recommendations for uniform risk and harm criteria for use in QRA globally and to suggest a risk-informed process for permitting fueling stations. Through journal publications and conference presentations, the results of this work have been disseminated as another resource for consideration and use by codes and standards groups and other decision makers [8-10]. 


\subsection{EXPANDING SAFETY KNOWLEDGE TOOLS AND RESOURCES}

Web-based resources are playing a key role in reaching, educating and informing stakeholders whose contributions will help enable the deployment of new hydrogen and fuel cell technologies $[11,12]$. Safety event information can serve as a rich and valuable resource if systematically collected, analyzed and used to enhance hydrogen safety knowledge.

Pacific Northwest National Laboratory (PNNL) work on the Hydrogen Incident Reporting and Lessons Learned database (http://h2incidents.org) has been an agenda topic since the Task 19 meeting in Vancouver in 2006. Safety event information sharing and the subsequent discussion have been invaluable in enhancing the value of the database since that time.

Building on collaborations initiated in Task 19, the project leads from PNNL and the European Commission's Joint Research Centre (JRC) shared the podium during a topical session on safety event databases $[13,14]$ and also provided online demonstrations of their respective tools at the September 2011 International Conference on Hydrogen Safety (ICHS) in San Francisco. The JRC and the International Association for Hydrogen Safety are responsible for the Hydrogen Incident and Accident Database (https://odin.jrc.ec.europa.eu/Hiad4/index.hiad) [15]. Safety event records are being shared between the two databases to enhance the value of each, and other collaborations between the two projects are being considered. The engaged interactions of Task 31 members help to ensure that safety knowledge tools such as the two discussed here are kept current, relevant to the community being served and valuable to the user.

\subsection{HYDROGEN SENSOR TECHNOLOGIES - BENEFITTING FROM COLLABORATION}

Many see hydrogen sensors as key devices for facilitating the safe production, storage, distribution and use of hydrogen. Their use is critical to detecting unwanted hydrogen leaks and to activating mitigative actions to reduce the potential hazards associated with theses leaks. Specifically, sensors have been used to sound audible alarms, activate ventilation systems and initiate shutdown of hydrogen systems to a safe stand-by state.

Despite the extensive research being channeled into developing smaller, faster, cheaper hydrogen sensors with improved performance characteristics, there is a lack of knowledge among sensor endusers regarding these developments and the correct choice or proper use of hydrogen sensing technology from the ever-increasing pool of commercial products. Furthermore, sensor manufacturers/developers lack an understanding of the performance requirements and expectations of sensor end-users. As a result, there is much to be gained from information exchange and knowledge dissemination in the development, selection and correct deployment of hydrogen safety sensors.

Task 31 meetings have provided excellent opportunities to collaborate and discuss sensor-related work. The collaboration between the U.S. Department of Energy National Renewable Energy Laboratory (NREL) and the JRC is a good example. Both NREL and the JRC Institute for Energy and Transport have established histories in performance testing of commercial-off-the-shelf hydrogen sensors under conditions representative of typical hydrogen applications. Through interactions facilitated by Task 31 meetings, the sensor collaboration was expanded to include the experts from the Natural Sciences and Engineering Research Council of Canada's Hydrogen Canada Strategic Research Network with expertise in microfabrication and microelectromechanical systems (MEMs), including the development of hydrogen sensors for MEMs. An assessment of miniaturized sensor technologies was presented recently at the World Hydrogen Energy Conference to highlight designs with improved performance [16]. The scope of this work has grown to include the performance evaluation of additional micro-machined commercial hydrogen sensors and a subsequent comparison with the performance of comparable conventional sensors. 


\subsection{DEVELOPING KNOWLEDGE TO IMPROVE GUIDELINES ON THE INDOOR USE OF HYDROGEN}

Hydrogen energy applications often require that systems be used indoors (e.g., industrial trucks for materials handling in a warehouse facility, fuel cells located in a room, and hydrogen stored and distributed from a gas cabinet). It may also be necessary or desirable to locate some hydrogen system components/equipment in indoor or outdoor enclosures for security or safety reasons to isolate them from the end-user and the public.

Use of hydrogen in confined environments requires detailed assessments of hazards and associated risks, including potential risk prevention and mitigation features. The release of hydrogen can potentially lead to the accumulation of hydrogen and the formation of a flammable hydrogen-air mixture.

Safety design guidelines and engineering tools need to be developed for use with specific safety strategies for these applications of hydrogen systems. Closing knowledge gaps is critical to this effort in several areas: hydrogen release conditions and accumulation, vented explosion and flame regimes (e.g., extinguishment or oscillating flames and steady burns). For each phenomena, the release position/conditions, the number, size and location of the openings in the room/enclosure of some given size, and the type of ventilation can significantly influence the prevention/mitigation strategy.

Task 19 and 31 meetings have played a significant role in building an overall comprehension of hydrogen phenomena and related knowledge gaps. Since 2009, the French Alternative Energies and Atomic Energy Commission has presented experimental work on the accumulation of helium in a garage, highlighting different accumulation regimes [17-20]. The National Institute of Standards and Technology presented similar work with a comparison with the Fire Dynamic Simulator [21], and Air Liquide presented existing engineering models for openings and vent sizing, highlighting the lack of experimental data on wind influence and on hydrogen vented explosions [22]. In 2011, SNL presented experiments of hydrogen release and ignition on a scaled warehouse. Modeling of the experimental results showed excellent reproductions using SNL's in-house RANS (Reynolds-averaged Navier-Stokes) based computational fluid dynamics (CFD) solver, FUEGO, to model the transient blowdown and dispersion into the enclosure and FLACS to model the cloud combustion at a specific ignition delay $[20,23]$. The University of Ulster presented the first work on the pressure peaking effect in case of a sudden large release of hydrogen in an enclosure, which could be caused by the activation of a thermally activated pressure relief device [24]. FM Global published new experimental results on vented deflagrations at ICHS4 [25]. In 2012, the first results of the French project DIMITRHY were presented by the French National Institute for Industrial Environment and Risks (INERIS) for experiments addressing hydrogen-vented explosions for different concentrations along with initial study of the influence of obstacles in the enclosure [26]. Air Liquide benchmarked vented explosion modeling [27] showing the over-prediction of some of the current CFD codes and noting the difficulty of simulating physical phenomena related to a so-called "external explosion."

The European Fuel Cell and Hydrogen Joint Undertaking project, HyIndoor, was launched in 2012 to address knowledge gaps and deliver guidelines and engineering tools on the safe design of natural ventilation and vent sizing for the indoor use of hydrogen. Collaboration to coordinate and discuss the research efforts and results through Task 31 would help ensure efficient use of the resources devoted to these aspects of hydrogen safety no matter where the work is performed.

\subsection{WHAT IS THE APPROPRIATE LEAN LIMIT?}

Tasks 19 and 31 have served as an ongoing forum for hydrogen safety experts to discuss important technical issues. The question of an appropriate hydrogen concentration lean limit that might lead to an explosion is a good example of such an issue. Identifying a meaningful lower limit that can lead to an explosion has significant safety implications, and several investigations among task experts have been conducted. 
Studies by the University of Miami [28], Ballard Power Systems [29], Defence R\&D Canada [30] and SNL [31] have established that mixtures below $~ 8 \%$ vol. of $\mathrm{H}_{2}$ in air are not robust enough to propagate a flame throughout an entire mixture, independent of geometry. Nor can a mixture below $\sim 8 \%$ vol. of $\mathrm{H}_{2}$ in air propagate a flame upstream of a fuel jet and stabilize at the jet exit. Mixture fractions above $8 \%$ vol. of $\mathrm{H}_{2}$ in air can sustain a flame, which may accelerate rapidly, resulting in significant quantities of hot post-flame gases and overpressure levels that can lead to a hazardous event harming life, equipment and facilities. The lower mixture fraction limit for this occurrence, which can be called a lower hazardous limit, is $8 \%$ vol. of $\mathrm{H}_{2}$ in air, which is higher than the formally established lower flammability limit for hydrogen: $4 \%$ vol. of $\mathrm{H}_{2}$ in air. At this concentration, flame propagation is only feasible in an upwards direction and only through a fully homogeneous quiescent mixture. From a safety perspective, we are interested in the lower hazardous limit of $8 \%$ vol. of $\mathrm{H}_{2}$ in air, not the lower flammability limit. Experts are working with code-developing organizations (e.g., the National Fire Protection Association and the International Organization for Standardization) to incorporate this knowledge into the model codes.

\subsection{A LIBRARY OF HAZARD ASSESSMENT TOOLS}

Extensive discussion within Task 31 recently led a group of collaborators (Karlsruhe Institute of Technology, SNL, Université du Québec à Trois-Rivières and AVT) to initiate a project to develop a hazard assessment engineering toolkit. The toolkit will contain validated tools, representing a consensus in the hydrogen community, that describe the physical properties of hydrogen releases and the consequences of their ignition, and contain the latest available failure frequency statistics and models. Key objectives will be to improve current models and develop new ones (e.g., incorporating surface effects on hydrogen jet behavior) and integrate both into the software library. The toolkit will also include recommended hydrogen release frequencies and component failure data and harm criteria for use in QRA. A user-friendly web interface and a spreadsheet calculator will help facilitate access to these tools and data.

The toolkit will target the hydrogen energy technology industry as a whole as well as industry sectors that use and manage hydrogen and hydrogen systems, e.g., the petroleum, nuclear and process industries. Users are expected to include designers and process engineers, insurance companies, authorities having jurisdiction and standardization agencies.

\subsection{CONCLUDING THOUGHTS}

As this paper illustrates, collaboration, information exchange and knowledge building can occur in many different ways. This white paper has provided examples of how the IEA HIA is addressing hydrogen safety-related barriers to facilitate the implementation and utilization of hydrogen and hydrogen-related systems. We should be encouraged to build on these successes by continuing to address high priority safety knowledge barriers via mechanisms that support collaborations of many types.

\subsection{ACKNOWLEDGMENTS}

The author wishes to thank the U.S. Department of Energy's Fuel Cell Technologies Program (Sunita Satyapal, Director) for support of U.S. participation in IEA HIA work on hydrogen safety. The editorial contributions in this white paper from Andrei Tchouvelev, Jeff LaChance, William Buttner, Lois Brett, Sidonie Ruban and Jay Keller are gratefully acknowledged. This white paper also appropriately recognizes the member countries and their hydrogen safety experts who have contributed to the body of technical work and information exchange that has been the hallmark of Tasks 19 and 31 since 2004. 


\subsection{REFERENCES}

1. International Energy Agency Hydrogen Implementing Agreement, http://ieahia.org/.

2. Jensen, J.K., Lymberopoulos, N., Pearce, S., and de Valladares, M-R., "IEA HIA: Research and Analysis that Enables Hydrogen Energy Solutions," World Hydrogen Energy Conference, Toronto, June 2012. (http://www.whec2012.com/wp-content/uploads/2012/07/ASR12.1.pdf)

3. Tchouvelev, A.V., "Knowledge Gaps in Hydrogen Safety, A White Paper," HIA Task 19, Revision 1, January 2008.

4. Håland, E., Paaske, B.J. and Engebø, A., "Survey of Hydrogen Risk Assessment Methods," Report No. 2005-1621, DNV Research and Innovation/HIA Task 19, Revision 2, January 2008.

5. Tchouvelev, A.V. and Ham, J.M., "Risk Assessment Studies of Hydrogen and Hydrocarbon Fueling Stations," HIA Revision 1, January 2008.

6. Weiner, S.C. and Blake, C.W., "Safety Knowledge Tools Enhanced by International Collaboration," A White Paper of the International Energy Agency Hydrogen Implementing Agreement Task 19 - Hydrogen Safety, PNNL-19901, October 18, 2010.

7. ISO/IEC Guide 51: 1999, Safety aspects - Guidelines for their inclusion in standards.

8. LaChance, J.L., Tchouvelev, A.V. and Engebø, A., "IEA Task 19 Hydrogen Safety Effort in Developing Uniform Risk Acceptance Criteria for the Hydrogen Infrastructure," Proceedings of the World Hydrogen Energy Conference, Brisbane, Australia, June 15-19, 2008.

9. LaChance, J.L., Tchouvelev, A.V. and Ohi, J., "Risk-informed Process and Tools for Permitting Hydrogen Fueling Stations," Int. J. Hydrogen Energy (2009).

10. LaChance, J.L., Tchouvelev, A.V. and Engebø, A., "Development of Uniform Harm Criteria for Use in Quantitative Risk Analysis of the Hydrogen Infrastructure," Int J Hydrogen Energy (2010).

11. Weiner, S.C., Fassbender, L.L., Blake, C., Aceves, S., Somerday, B.P. and Ruiz, A., "Web-based Resources Enhance Hydrogen Safety Knowledge," PNNL-SA-82812/83988, HYPOTHESIS IX, San José, Costa Rica, December 12-15, 2011.

12. Weiner, S.C., Fassbender, L.L., Blake, C., Aceves, S., Somerday, B.P. and Ruiz, A., "Web-Based Resources Enhance Hydrogen Safety Knowledge," International Journal of Hydrogen Energy, Volume 38 (2013), pp. 7583-7593.

13. Weiner, S.C. and Fassbender, L.L., "Lessons Learned from Safety Events," PNNL-SA-78868, International Conference on Hydrogen Safety, San Francisco, CA, September 12-14, 2011.

14. Galassi, M.C., Papanikolaou, E., Baraldi, D., Funnemark, E., Håland, E., Engeb $\varnothing$, A., Haigom, G.P., Jordan, T. and Tchouvelev, A.V., "HIAD, Hydrogen Incident and Accident Database," International Conference on Hydrogen Safety, San Francisco, CA, September 12-14, 2011.

15. Galassi, M.C., Papanikolaou, E., Baraldi, D., Funnemark, E., Håland, E., Engeb $\varnothing$, A., Haigom, G.P., Jordan, T. and Tchouvelev, A.V., "HIAD, Hydrogen Incident and Accident Database," Int. J. Hydrogen Energy (2012).

16. Domingue, F., El Matbouly, H., Buttner, W., Burgess, R., Brett, L. and Palmisano, V., "The Promise and Pitfalls of Micro-Machined Hydrogen Sensors," World Hydrogen Energy Conference, Toronto, Canada, June 3-7, 2012. (http://www.whec2012.com/wpcontent/uploads/2012/06/WHEC2012-Sensors Hatem 22.pdf)

17. Cariteau, B., Brinster, J. and Tkatschenko, I., "Experiments on the Distribution of Concentration due to Buoyant Gas Low Flow Rate Release in an Enclosure," International Conference on Hydrogen Safety, Ajaccio, Corsica, France, September 2009.

18. Cariteau, B. and Tkatschenko, I., "Experimental Study of the Concentration Build-up Regimes in an Enclosure Without Ventilation," International Conference on Hydrogen Safety, San Francisco, CA, September 12-14, 2011. 
19. Cariteau, B. and Tkatschenko, I., "Experimental Study of the Effects of Vent Geometry on the Dispersion of a Buoyant Gas in a Small Enclosure," International Conference on Hydrogen Safety, San Francisco, CA, September 12-14, 2011.

20. Houf, W.G., Evans, G.H., Ekoto, I.W., Merilo, E.G. and Groethe, M.A., "Hydrogen Fuel-Cell Forklift Vehicle Releases in Enclosed Spaces," International Conference on Hydrogen Safety, San Francisco, CA, September 12-14, 2011.

21. Pitts, W., Yang, J. and Prasad, K., "Experimental Characterization of a Helium Dispersion in a $1 / 4$ Scale Two-car Residential Garage," IEA Hydrogen Implementing Agreement Task 19 Experts Meeting, April 23, 2009.

22. Jallais, S. and Ruban, S., "Engineering Tools and Methods for Dispersion and Explosion Vent Sizing," IEA Hydrogen Implementing Agreement Task 19 Experts Meeting, Ajaccio, Corsica, France, September 14, 2009.

23. Ekoto, I.W., Houf, W.G., Evans, G.H., Merilo, E.G. and Groethe, M.A., "Experimental Investigation of Hydrogen Release and Ignition from Fuel Cell Powered Forklifts in Enclosed Spaces," International Conference on Hydrogen Safety, San Francisco, CA, September 12-14, 2011.

24. Molkov, V., "Fundamentals of Hydrogen Safety Engineering, Part 1," pp. 114-124, www.bookboon.com.

25. Bauwens, C., Chao, J. and Dorofeev, S., "Effects of Hydrogen Concentration on Vented Explosion Overpressures from Lean Hydrogen-Air Deflagrations," International Conference on Hydrogen Safety, San Francisco, CA, September 12-14, 2011.

26. Daubech, J. and Proust, C. "Vented Hydrogen-Air Deflagrations: Some Experimental Results," IEA Hydrogen Implementing Agreement Task 31 Experts Meeting, Paris, France, April 17, 2012.

27. Jallais, S., Vyzmina, E., Kudriakov, S., Studer, E. and Verbecke, F., "Vented Explosion Benchmark Exercise: CFD and Engineering Models," IEA Hydrogen Implementing Agreement Task 31 Experts Meeting, Paris, France, April 17, 2012.

28. Swain, M.R., Filoso, P.A. and Swain, M.N., "An Experimental Investigation into the Ignition of Leaking Hydrogen,” Int. J. Hydrogen Energy, 32, No. 2, 2007, pp. 287-295.

29. Corfu, R., DeVaal, J. and Scheffler, G., "Development of Safety Criteria for Potentially Flammable Discharges from Hydrogen Fuel Cell Vehicles," SAE Technical Paper 2007-01-0437, 2007.

30. Désilets, S., Côté, S., Nadeau, G. and Tchouvelev, A.V., "Ignition Experiments of Hydrogen Mixtures by Different Methods and Description of the DRDC Test Facilities," International Conference on Hydrogen Safety, Ajaccio, Corsica, France, September 2009.

31. Moen, C. and Keller, J., "Hydrogen Testing Capability at Sandia National Laboratories," IEA HIA Task 19 Experts Meeting, Joint Workshop on Hydrogen Safety and Risk Assessment, Long Beach, CA, March 16-17, 2006. 